\title{
Dogfish $\mathbf{M}_{4}$ Lactate Dehydrogenase: Reversible Inactivation by Pyridoxal 5'-Phosphate and Complete Protection in Complexes that Mimic the Active Ternary Complex
}

\author{
By Soo-Se Chen and Paul C. Engel \\ Department of Biochemistry, University of Sheffield, Sheffield S10 2TN, U.K.
}

\section{(Received 1 August 1975)}

\begin{abstract}
Dogfish $\mathrm{M}_{4}$ lactate dehydrogenase, like the corresponding pig enzyme, is inactivated by pyridoxal 5'-phosphate through modification of a single essential lysine residue. The activity is completely protected in the complexes E-NAD ${ }^{+}$-oxalate, E-NADH-oxamate and $\mathrm{E}-\left(\mathrm{NAD}^{+}-\right.$pyruvate adduct $)$, but only partially protected in $\mathrm{E}-\mathrm{NAD}^{+}, \mathrm{E}-\mathrm{NADH}$, E-NAD ${ }^{+}$-oxamate and E-NADH-oxalate.
\end{abstract}

Pig muscle $\mathrm{M}_{4}$ lactate dehydrogenase (EC 1.1.1.27) is reversibly inactivated by the reaction of pyridoxal 5'-phosphate with an essential lysine residue (Chen \& Engel, 1975b). This covalent modification is completely prevented by the addition of $\mathrm{NAD}^{+}$and pyruvate, which form an adduct tightly bound at the active site of the enzyme (Arnold \& Kaplan, 1974, and references cited therein). Identification of the essential lysine residue might give a clearer indication of its likely role, but lactate dehydrogenase from dogfish muscle is the obvious choice for such work, since it has been used for most of the structural studies (Adams et al., 1973). It is important as a first step, therefore, to establish that the dogfish and pig lactate dehydrogenases react similarly with pyridoxal 5'-phosphate.

In this present study of the reaction of dogfish muscle lactate dehydrogenase with pyridoxal 5'phosphate we have paid special attention to the extent of protection of the enzyme in its various ternary complexes.

\section{Materials and methods}

Dogfish (Squalus acanthius) $\mathbf{M}_{4}$ lactate dehydrogenase, purified at the final stage by affinity chromatography on an AMP-Sepharose column (Lowe \& Dean, 1974), was a gift from Dr. P. D. G. Dean, University of Liverpool, Liverpool, U.K. Coenzymes were obtained from Boehringer Corp. (London) Ltd., London W5 2TZ, U.K. Lithium lactate and sodium oxamate were products of Sigma (London) Chemical Co., Kingston-upon-Thames, Surrey, U.K. Sodium pyruvate and oxalic acid were supplied by Koch-Light Laboratories Ltd., Colnbrook, Bucks., U.K. All other materials and procedures were as described previously (Chen \& Engel, 1975b).

\section{Results and discussion}

Incubation of dogfish $\mathrm{M}_{4}$ lactate dehydrogenase with $2 \mathrm{~mm}$-pyridoxal $5^{\prime}$-phosphate in $0.05 \mathrm{M}$-sodium pyrophosphate buffer, $\mathrm{pH} 8.5$, at $25^{\circ} \mathrm{Cled}$ to a gradual decline in catalytic activity, and within $20 \mathrm{~min}$ a steady value of residual activity, $20 \%$ of the initial value, was attained. Higher extents of inactivation could not be achieved by increasing the concentration of pyridoxal 5'-phosphate. Dialysis fully restored catalytic activity. When the modified enzyme was reduced with $\mathrm{NaBH}_{4}$, however, the inactivation became irreversible. This is expected if the inactivation involves reaction of the $\varepsilon$-amino group of a lysine residue with the aldehyde function of the modifier to yield a Schiff base. The absorption spectrum of the enzyme after irreversible inactivation and dialysis indicates (Fischer et al., 1963) that $3.8 \mathrm{~mol}$ of lysine/ mol of enzyme subunit reacts in this way.

The effects of the chemical modification on the kinetic properties of the enzyme were studied. Initial rates of reaction in $0.1 \mathrm{M}$-potassium phosphate buffer, $\mathrm{pH} 8$, at $25^{\circ} \mathrm{C}$ were measured with varied $\mathrm{NAD}^{+}$concentrations (22-220 $\mu \mathrm{M}$ with $5 \mathrm{mM}$-lactate) and with varied lactate concentrations $(2-20 \mathrm{~mm}$ with $\left.110 \mu \mathrm{M}-\mathrm{NAD}^{+}\right)$. Within experimental error the apparent $K_{m}$ values for $\mathrm{NAD}^{+}(330 \mu \mathrm{M})$ and lactate $(38 \mathrm{~mm})$ were identical for native enzyme and for enzyme irreversibly inactivated as described above and dialysed. The corresponding apparent maximum velocities of reaction were decreased fivefold by the chemical treatment. An enzyme sample dialysed without $\mathrm{NaBH}_{4}$ reduction after treatment with pyridoxal 5'-phosphate gave the same kinetic constants as the native enzyme.

Qualitatively these results are very similar to those obtained with pig $\mathbf{M}_{4}$ lactate dehydrogenase, although the extent of inactivation achieved in a single treatment with pyridoxal $5^{\prime}$-phosphate $(70 \%)$ was somewhat less for the pig enzyme. The initial-rate measurements indicate that the chemical modification converts native enzyme into a totally inactive form.

As for several other dehydrogenases (see references cited in Chen \& Engel, 1975b) the likely explanation of the persistence of activity even after incubation with pyridoxal 5 '-phosphate at saturating concentrations is that the inactive species is in equilibrium with 
a rapidly dissociable enzyme-pyridoxal 5 -phosphate complex. If so, a second treatment with pyridoxal 5 '-phosphate after reduction and dialysis should further inactivate the enzyme (Chen \& Engel, 1975a). Three successive treatments of dogfish $\mathbf{M}_{4}$ lactate dehydrogenase with 2mM-pyridoxal 5 '-phosphate decreased the activity to $19.6 \%, 4.2 \%$ and finally $1.5 \%$ of its initial value. The value of $4.2 \%$ is very close to $19.6 \%$ of $19.6 \%$ (i.e. $3.8 \%$ ). Such a geometric progression of inactivation is theoretically predicted if a single essential lysine residue is modified in each inactivated enzyme subunit. This pattern has also been observed in the reactions of pyridoxal 5'-phosphate with bovine glutamate dehydrogenase and horse alcohol dehydrogenase (Chen \& Engel, $1975 c$ ), but is less closely followed in the case of pig $\mathbf{M}_{4}$ lactate dehydrogenase, implying, perhaps, interference by other non-essential lysine residues (Chen \& Engel, 1975b).

The substrates, lactate and pyruvate, and their inhibitory analogues, oxalate and oxamate, at concentrations up to $10 \mathrm{mM}$, give no protection against inactivation when included in incubations of dogfish $\mathbf{M}_{4}$ lactate dehydrogenase with pyridoxal 5'-phosphate (Table 1). Even at saturating concentrations, the coenzymes $\mathrm{NAD}^{+}$and NADH gave only partial protection, resulting in residual activities of 55.8 and

Table 1. Effects of coenzymes and substrates or substrate analogues on the equilibrium position of the inactivating reaction between dogfish $M_{4}$ lactate dehydrogenase and pyridoxal 5'-phosphate: activity measured without $\mathrm{NaBH}_{4}$ reduction

Conditions were as follows. Dogfish $\mathrm{M}_{4}$ lactate dehydrogenase $(0.02 \mathrm{mg} / \mathrm{ml})$ was incubated with $2 \mathrm{~mm}$-pyridoxal $5^{\prime}$-phosphate at $25^{\circ} \mathrm{C}$ in $0.05 \mathrm{M}$-sodium pyrophosphate buffer, pH 8.5, with the additions listed. At timed intervals $5 \mu \mathrm{l}$ samples were taken for activity assays. The residual activity after $60 \mathrm{~min}$, when the inactivation reaction had clearly reached equilibrium, is given below.

Addition

\section{None}

10 mm-Lactate

$10 \mathrm{~mm}$-Pyruvate

$10 \mathrm{~mm}$-Oxalate

$10 \mathrm{~mm}$-Oxamate

$1 \mathrm{mM}-\mathrm{NAD}^{+}$

$4 \mathrm{mM}^{-N^{2} D^{+}}$

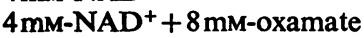

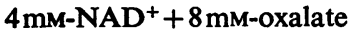

0.1 MM-NADH

0.5 mM-NADH

0.5 mM-NADH + 8mM-oxamate

$0.5 \mathrm{~mm}$-NADH + $8 \mathrm{~mm}$-oxalate

$0.5 \mathrm{~mm}-\mathrm{NADH}+8 \mathrm{~mm}$-lactate
$75.5 \%$ respectively at equilibrium (Table 1 ). These findings closely match those for the pig $\mathrm{M}_{4}$ enzyme, and their significance is discussed in our earlier paper (Chen \& Engel, 1975b).

It is known that lactate dehydrogenase undergoes a marked conformational change in the transition from a binary enzyme-coenzyme complex to a ternary complex (Rossmann et al., 1972). It was therefore decided to investigate whether the essential lysine residue is more completely protected in ternary than in binary complexes. Table 1 shows that inactivation by 2 mM-pyridoxal 5 '-phosphate was completely prevented by $0.5 \mathrm{~mm}$-NADH with $8 \mathrm{~mm}$-oxamate, and by $4 \mathrm{~mm}-\mathrm{NAD}^{+}$with $8 \mathrm{~mm}$-oxalate. On the other hand, oxamate did not augment the protection given by $\mathrm{NAD}^{+}$alone, nor did oxalate augment that given by NADH alone. Kinetically, oxalate and oxamate behave as analogues of lactate and pyruvate respectively (Winer \& Schwert, 1959; Novoa et al., 1959; Novoa \& Schwert, 1961). Thus it appears that the essential lysine residue is fully protected only in complexes that mimic the productive ternary complex.

Rossmann et al. (1972) have shown that crystals of enzyme-NADH-oxamate and of enzyme-NAD ${ }^{+}-$ oxalate are isomorphous with those of the complex formed by the enzyme with the inhibitory pyruvate$\mathrm{NAD}^{+}$adduct, but not with crystals of unliganded enzyme. In all three complexes the loop of residues $100-120$ is folded down. One might therefore expect complete protection by the pyruvate- $\mathrm{NAD}^{+}$adduct in our system. The degree of protection by this compound, however, cannot be ascertained simply by assaying the equilibrium mixture, because the adduct itself inactivates the enzyme. Consequently the extent of inactivation by pyridoxal 5 -phosphate in the presence of the adduct can only be determined by reducing the equilibrated inactivation mixture with $\mathrm{NaBH}_{4}$ and dialysing. Under these conditions only the inactivation by the pyruvate-NAD ${ }^{+}$adduct is reversed. Table 2 shows the results of a protection study of this type. Absorption measurements at $327 \mathrm{~nm}$ (Fischer et al., 1963) allow correlation of the extent of inactivation with the stoicheiometry of incorporation of pyridoxal $5^{\prime}$-phosphate in the presence and in the absence of protecting agents.

The combination of $\mathrm{NAD}^{+}(4 \mathrm{~mm})$ and pyruvate (4mM) completely protected dogfish $M_{4}$ lactate dehydrogenase against inactivation by $4 \mathrm{~mm}$-pyridoxal 5'-phosphate (Table 2). Formation of the pyruvate$\mathrm{NAD}^{+}$adduct under these conditions was established in separate experiments in which the enzyme was incubated with pyruvate and $\mathrm{NAD}^{+}$in the absence of pyridoxal $5^{\prime}$-phosphate. In preserving the $80 \%$ of the activity that would otherwise have been lost, the adduct also protected approx. $0.8 \mathrm{~mol}$ of lysine $/ \mathrm{mol}$ of enzyme subunit. This again implies that modification of a single essential lysine residue per subunit is 
Table 2. Effects of coenzymes, substrates and substrate analogues on the reaction between dogfish $M_{4}$ lactate dehydrogenase and pyridoxal 5'-phosphate: activity and stoicheiometry of lysine modification measured after $\mathrm{NaBH}_{4}$ reduction

Conditions were as follows. Dogfish $\mathrm{M}_{4}$ lactate dehydrogenase $(1 \mathrm{mg} / \mathrm{ml})$ was incubated with $4 \mathrm{~mm}$-pyridoxal $5^{\prime}$-phosphate and the protecting agents indicated in $0.05 \mathrm{M}$-sodium pyrophosphate buffer, $\mathrm{pH} 8.5$, at $25^{\circ} \mathrm{C}$ for $30 \mathrm{~min}$, reduced with $\mathrm{NaBH}_{4}$ and dialysed. The number of lysine residues modified was estimated from the optical absorbance at $327 \mathrm{~nm}$ (see the text). A control sample incubated as described but in the absence of pyridoxal 5 -phosphate retained full activity.

\begin{tabular}{|c|c|c|}
\hline Added protecting agent & $\begin{array}{c}\text { Residual } \\
\text { activity } \\
(\%)\end{array}$ & $\begin{array}{l}\text { Lysine } \\
\text { residues } \\
\text { modified } \\
\text { (mol/mol of } \\
\text { enzyme } \\
\text { subunit) }\end{array}$ \\
\hline None & 19.6 & 3.8 \\
\hline $4 \mathrm{mM}^{-N A D^{+}}$ & 50.7 & 3.5 \\
\hline $4 \mathrm{mM}^{-\mathrm{NAD}^{+}+4 \mathrm{~mm} \text {-pyruvate }}$ & 98.3 & 3.0 \\
\hline $4 \mathrm{~mm}-\mathrm{NAD}^{+}+4 \mathrm{~mm}$-oxamate & 55.9 & 3.4 \\
\hline 1 mM-NADH & 76.2 & 3.3 \\
\hline $1 \mathrm{~mm}-\mathrm{NADH}+4 \mathrm{~mm}$-oxamate & 101.6 & 2.9 \\
\hline $8 \mathrm{~mm}$-Pyruvate & 20.2 & 3.8 \\
\hline
\end{tabular}

responsible for the inactivation by pyridoxal $5^{\prime}$ phosphate.

The other results in Table 2 confirm those of Table 1 with respect to the lack of protection by pyruvate, the partial protection by $\mathrm{NAD}^{+}$and $\mathrm{NADH}$, and the complete protection by NADH plus oxamate. In all cases there was approximately a one-to-one relation between the number of active subunits protected and the decrease in the number of lysine groups modified.

In conclusion, it appears that in dogfish $\mathbf{M}_{4}$ lactate dehydrogenase, as in the pig $\mathbf{M}_{4}$ enzyme, the modification of a single lysine residue by pyridoxal 5'phosphate abolishes catalytic activity. This residue is not indispensable for coenzyme binding, since neither coenzyme protects it completely. On the other hand, the formation of ternary complexes analogous in structure to the productive ternary complex involved in catalysis prevents modification of the essential lysine residue. This is consistent with a catalytic role for the essential residue or an involvement in substrate binding, but other interpretations are also possible (Chen \& Engel, 1975b). Although the modifier reacts with other, non-essential, lysine residues, the possiblity of specific and complete protection of the essential residue should facilitate its labelling and identification. This in turn should permit a better-informed guess as to the function of the essential lysine residue.

The support of the Science Research Council and of the Wellcome Foundation is gratefully acknowledged.

Adams, M. J., Buehner, M., Chandrasekhar, K., Ford, G. C., Hackert, M. L., Liljas, A., Rossmann, M. G., Smiley, I. E., Allison, W. S., Everse, J., Kaplan, N. O. \& Taylor, S. S. (1973) Proc. Natl. Acad. Sci. U.S.A. 70, 1968-1972

Arnold, L. J., Jr. \& Kaplan, N. O. (1974) J. Biol. Chem. 249, 652-655

Chen, S.-S. \& Engel, P. C. (1975a) Biochem.J. 147, 351-358

Chen, S.-S. \& Engel, P. C. (1975b) Biochem. J. 149, 107-113

Chen, S.-S. \& Engel, P. C. (1975c) Biochem.J. 149, 627-635

Fischer, E. H., Forrey, A. M., Hedrick, J. L., Hughes, R. C., Kent, A. B. \& Krebs, E. G. (1963) in Chemical and Biological Aspects of Pyridoxal Catalysis (Snell, E. E., Fasella, P. M., Braunstein, A. \& Rossi-Fanelli, A., eds.), p. 543, Pergamon Press, Oxford

Lowe, C. R. \& Dean, P. D. G. (1974) Affinity Chromatography, Wiley-Interscience, London

Novoa, W. B. \& Schwert, G. W. (1961) J. Biol. Chem. 236, 2150-2153

Novoa, W. B., Winer, A.D., Glaid, A. J. \& Schwert, G. W. (1959) J. Biol. Chem. 234, 1143-1148

Rossmann, M. G., Adams, M. J., Buehner, M., Ford, G. S., Hackert, M. L., Lentz, P. J., Jr., McPherson, A., Jr., Schevitz, R. W. \& Smiley, I. E. (1972) Cold Spring Harbor Symp. Quant. Biol. 36, 179-191

Winer, A. D. \& Schwert, G. W. (1959) J. Biol. Chem. 234, 1155-1161 